munications are grouped in four sections. In the first section, three papers examine the interaction of drugs with DNA. Roberts, Brent and Crathorn discuss the alkylation of DNA by mustard gas and the biological consequences of the damage and its repair. Rees provides a condensed and simplified account of the interactions of antibiotics with DNA, pointing out the different modes of attack found with substances such as actinomycin, mitomycin and daunomycin. Prusoff completes this section with a useful account of the nature and consequences of substitution of DNA bases with analogues. The second section deals with cytoplasmic organelles and opens with an account by Chappell and co-workers of transport in mitochondria with some discussion of the actions of drugs thereon. Orrenius contributes an interesting paper on the response of liver to drugs and the nature of the induced enzymatic activity following phenobarbital administration. Korner follows with an account of antibiotics which affect protein synthesis, while Weisberger deals with the actions of chloramphenicol in mammalian systems. Both of these contributions suffer from restriction to mammalian systems when so much more has been learned from studies with the corresponding bacterial systems, and it is curious to read a paper on chloramphenicol which makes no reference to the differing binding capacities of ribosomes from different types of cells and organelles. Weisberger proposes a mechanism of action of chloramphenicol in mammalian tissues which is quite different from that which has been developed for bacterial ribosomes; acceptance of his proposal would need a critical assessment of the experimental systems and evidence on which it is based.

The second half of the symposium starts with the importance of lysosomes and their activities as targets for drug action. De Duve displays the field; Lloyd and co-workers track down the action of acid bisazo dyos; Weissman discusses the possibility that anti-inflammatory drugs influence lysosomes, and Allison investigates the collection of a wide range of toxic agents and drugs in lysosomes and its consequences. The final section of the symposium moves away from the theme of externally administered drugs and deals with particles and norve structures concerned with the elaboration and secretion of humoral agents. Smith contributes a detailed description of the adrenal chromaffin granules; Potter discusses the uptake of choline by nerve endings, and Hope and Dean investigate the character and activities of the neurosecretory granules of the posterior pituitary. The whole symposium is admirably summarized by Bergel.

The volume sets out information which is valuable to all those working in the fields of drug action and chemotherapy. A symposium limited in time to two days must be limited in other ways, and the organizers have chosen to restrict the discussion to mammalian systems. This has brought together much information not previously available in one publication but results in an incomplete and unbalanced picture of present knowledge of interactions between drugs and cell components in general.

E. F. Gale

\section{FAMILY PSYCHIATRY}

Theory and Practice of Family Psychiatry

By John G. Howells. With edited contributions. Pp. xi+953. (Oliver and Boyd: Edinburgh and London, 1968.) $189 s$.

THIs massive volume is really two books in one-an exposition by its editor/part-author, Dr J. G. Howells, of his personal formulation of the theory and practice of family therapy; and a collection of clinical and research papers, with a bearing on family processes, by some seventy authors. One or two of these papers have been written or revised for this publication; the majority have been culled from the psychiatric and sociological literature of the past twenty years. They include most of the leading names in this field-from Ackerman, Alanen and Bateson right through the alphabet to Singer and Wynne, Tucker and Youngman.

Some of the articles reproduced (albeit in edited versions) are of lasting importance, so that it is rewarding to have them in one volume. Among these are the classic paper "Towards a Theory of Schizophrenia" by Bateson et al., the Wynne-Singer "Thought Disorders and Family Relations of Schizophrenics", and the Hilgard-Newman study of "Anniversaries in Mental Illness". Some of the other celebrities are represented by articles which do less than full justice to their research in this field.

Throughout this volume, articles reporting factual, statistically analysed enquiries alternate with clinical expositions which have an undisguisedly dogmatic flavour. Dr Howells himself appears to be very confident of the importance of his own obiter dicta. In the opening sentence of his book he appears to claim a copyright in the term "Family psychiatry"; and in the succeeding sentence he declares "Individual psychiatry ... is obsolete". His first chapter is brief, and cites only a book and a paper by Howells; but the two following chapters occupy 110 pages and contain no fewer than 1,071 references. Inevitably, most of these contributions are mentioned rather than critically discussed. It might well be argued that this very mixture of systematic enquiry, unsupported assertions and therapeutic confidence faithfully represents the present state of development of family psychiatry; and no one who reads this book will doubt that its author is one of its most energetic proponents.

\section{G. M. Carstairs}

\section{COLOUR VISION}

\section{Human Color Perception}

A Critical Study of the Experimental Foundation. By Joseph J. Sheppard, jun. Pp. xvii + 192. (EIsevier New York and Barking, Essex, 1968.) $120 s$.

THE author has recently turned his interest in bioengin eoring to vision, and his book is based on two study reports which had been prepared for the Rand Corporation. It contains nine short chapters and there are also 245 references and an appendix defining terms and symbols used for radiant and luminous energy.

The first two chapters are about the relationship between physies, physiology and psychology in the study of vision and include a brief description of the visual pathway. The third chapter, on the CIE observer, deals competently with the standard photopic, scotopic and colour matching functions. The next two chapters on retinal sensitivity and physiology review spectral sensitivity functions derived by psychophysical methods. An extensive comment on the appearance of secondary peaks in these functions would have been more valuable had some consideration been given to the absorptive properties of pre-retinal media. An account of spectrodensitometry of extracted visual pigments, single photoreceptors, and of fundus reflectometry is included with some notes on the histology, geometry and metabolism of rods and cones. The graded achromatic and chromatic electrophysiological responses of lower vertebrates are described. The sixth chapter on cerebral physiology deals mainly with the anatomy and chromatic responses of the primate lateral geniculate nucleus. Some introductory remarks on the evolution of the visual pathway provide a useful link with the preceding chapter. Chapter 7 on psychophysiology describes aspects of achromatic and chromatic light adaptation, adaptation to visual field inversion, and concludes with an enthusiastic but rather extensive critique of Lands' two-colour projection experiments. Chapter 8 on temporal phenomena is a 